\section{CASE REPORT}

Y. Wang

H. Shi

\title{
Dedifferentiated Liposarcoma of the Neck: CT Findings
}

SUMMARY: We report a case of DDL with an osteosarcomatous component affecting the right neck. CT showed a lipomatous region with thick septa, a low-attenuation high-water-content component, and a sporadic heterogeneous high-attenuation calcified area.

ABBREVIATIONS: DDL = dedifferentiated liposarcoma; $\mathrm{HE}=$ hematoxylin-eosin; WDL $=$ welldifferentiated liposarcoma

iposarcoma is one of the most common soft-tissue sarcomas. It is currently classified into 5 subtypes: well-differentiated, dedifferentiated, myxoid, pleomorphic, and mixed. ${ }^{1}$ DDL represents a biphasic neoplasm, with 1 component being a WDL and the other a nonadipose cellular sarcoma. The most common dedifferentiated component is undifferentiated pleomorphic sarcoma or fibrosarcoma. Dedifferentiation to osteosarcoma is rare, and only 8 cases, to our knowledge, have been described in the literature..$^{2-9}$

We report a case of a young woman who had DDL of the neck with an osteosarcomatous component, to illustrate the imaging and pathologic findings.

\section{Case Report}

A 20-year-old woman presented with a painless mass in the right neck, which had been progressively enlarging for approximately 2 months. On physical examination, the right neck was markedly larger than the left. An oral examination revealed a submucosal bulging of the right lateral pharyngeal wall. The overlying mucosa appeared to be

Received September 22, 2010; accepted after revision October 20.

From the Department of Oral and Maxillofacial Surgery (Y.W.), Shanghai Ninth People's Hospital, Medical School, Shanghai Jiao Tong University, Shanghai Key Laboratory of Stomatology, Shanghai, P. R. China; and Department of Radiology (H.S.), Shanghai Ninth People's Hospital, Medical School, Shanghai Jiao Tong University, Shanghai, P. R. China.

Please address correspondence to Huimin Shi, MD, Department of Radiology, Shanghai Ninth People's Hospital, Medical School, Shanghai Jiao Tong University, No. 639, Zhi Zao Ju Rd, Shanghai 200011, P. R. China; e-mail: shihuimin@msn.com http://dx.doi.org/10.3174/ajnr.A2431
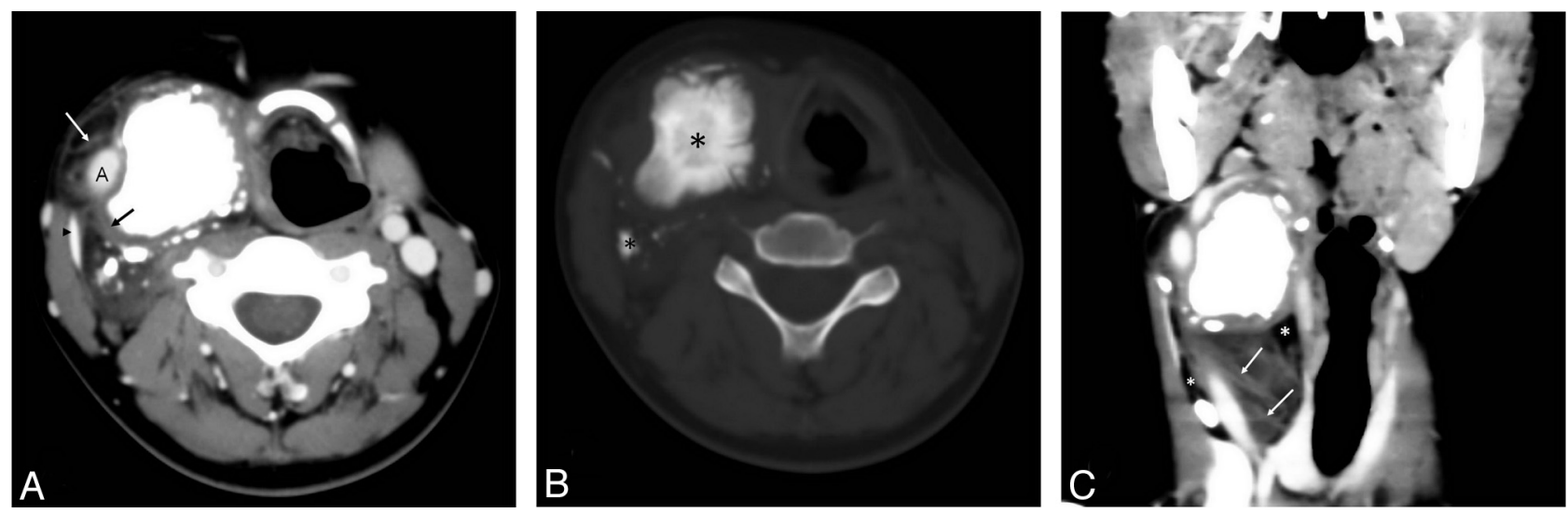

Fig 1. A, Contrast-enhanced axial CT scan shows lipomatous regions with thick septa (white arrow), a low-attenuation high-water-content component (black arrow), and sporadic heterogeneous high-attenuation calcified areas in the right common carotid space. The mass surrounds the right common carotid artery and displaces the jugular vein (black arrowhead) laterally. $B$, In this precontrast axial CT scan with a bone algorithm, the tumor ossification (black asterisks) is evident. C, A multiplanar reformatted image shows the mass with well-defined margins between the sternocleidomastoideus muscle and the lateral pharyngeal wall, displacing the right jugular vein. Thick septa (white arrows) and fat (white asterisks) are noted. 


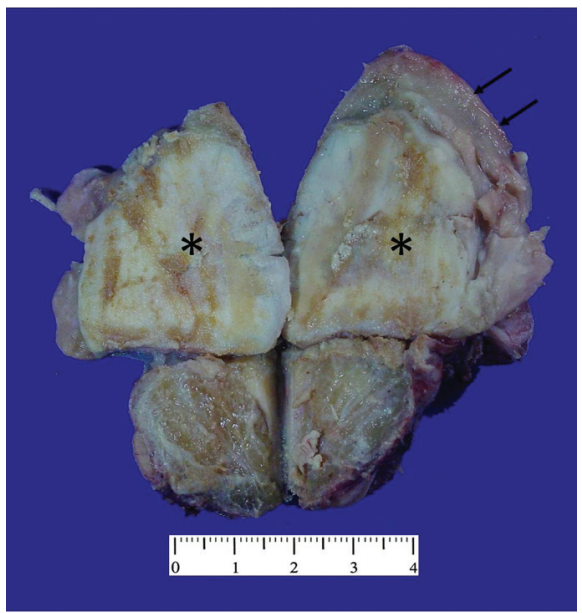

Fig 2. Photograph of the gross specimen shows the intramuscular sclerotic bone-forming lesion (black asterisks) with sharply delineated lipomatous caps (black arrows).

The areas of dedifferentiation are usually larger than $3 \mathrm{~cm}$ at imaging. ${ }^{10}$ The Armed Forces Institute of Pathology reported that $8.9 \%$ of all liposarcomas are dedifferentiated lesions, with $28.5 \%$ in the extremities, $66 \%$ in the retroperitoneum, and $6 \%$ in other locations. ${ }^{11}$

To the best of our knowledge, this is the ninth case of a DDL with osteosarcoma and the first case located in the neck reported in the literature. ${ }^{2-9}$

Radiographically, CT appearances of lipomatous tumors are based on the distribution of the fat and nonfat components, and patterns are classified into 3 types $^{12}$ : Type A tumors, homogeneous fatty tumors, are low-grade lipomatous neoplasms, including lipoma and lipomalike liposarcoma. Type B tumors, fat-attenuation tumors intermingled with higher attenuation components, are higher grade liposarcomas, including myxoid and mixed liposarcoma with pleomorphic or small cell types. Type $\mathrm{C}$ tumors, complex tumors containing both a fat component and a well-defined nonfatty component, are the typical pattern of DDL. ${ }^{12}$

In our case, osteosarcomatous components were approximately $5 \mathrm{~cm}$. Calcification or ossification is a distinct imaging

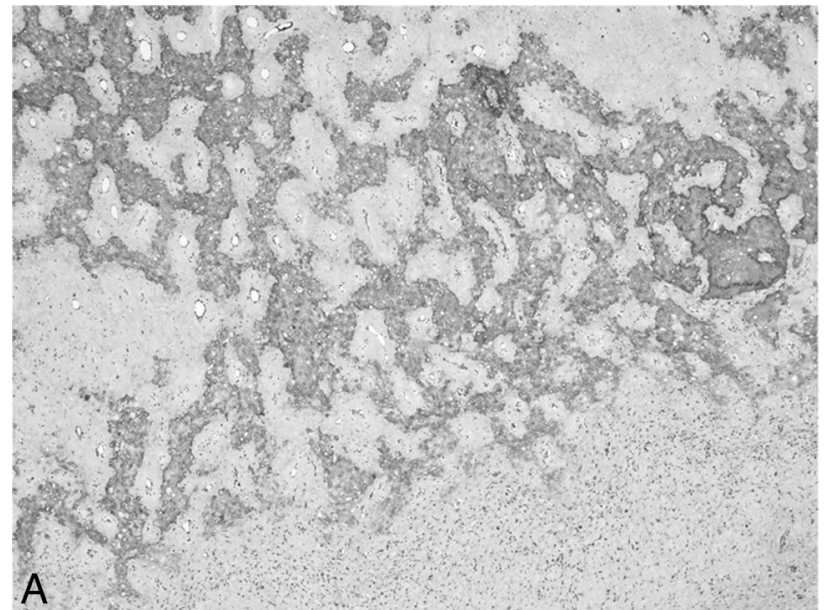

pattern of DDL. Osteosarcomatous and chondrosarcomatous dedifferentiation is the cause of such mineralization.

In the neck, the differential diagnosis for DDL with osteosarcomatous components and teratoma may be troublesome radiographically. CT of a teratoma demonstrates heterogeneous solid, fatty tissue, and cystic mass with specks of calcification. ${ }^{13}$ Other head and neck tumors that have fatty tissue include lipomas and lipoblastomas.

The clinical behavior of DDL, which reflects the highgrade histologic characteristics of most of these lesions, is more aggressive than well-differentiated liposarcomas. DDLs are treated with wide surgical excision and frequently with radiation therapy; chemotherapy may also be used as an adjunct. The disease is characterized by a tendency to recur locally in at least $40 \%$ of cases. ${ }^{1,14-19}$ Distant metastases are observed in $15 \%-20 \%$ of cases, with an overall mortality rate of $28 \%-30 \%$ at 5-year follow-up. ${ }^{3,20,21}$

\section{Conclusions}

We describe a case of DDL with an osteosarcomatous component in the neck. Radiologists should be familiar with the different location, and this case emphasizes the wide spectrum of DDL.

\section{References}

1. Fletcher CDM, Unni KK, Mertens F, for the International Agency for Research. Pathology and Genetics of Tumours of Soft Tissue and Bone: IARC WHO Classification of Tumours. Lyon, France: IARC Press; 2002:38-39

2. Toshiyasu T, Ehara S, Yamaguchi T, et al. Dedifferentiated liposarcoma of the retroperitoneum with osteosarcomatous component: report of two cases. Clin Imaging 2009;33:70-74

3. Henricks WH, Chu YC, Goldblum JR, et al. Dedifferentiated liposarcoma: clinicopathological analysis of 155 cases with a proposal for an expanded definition of dedifferentiation. Am J Surg Pathol 1997;21:271-81

4. Toms AP, White LM, Kandle R, et al. Low-grade liposarcoma with osteosarcomatous dedifferentiation: radiological and histological features. Skeletal Radiol 2003;32:286-89

5. Evans HL. Liposarcoma: a study of 55 cases with a reassessment of its classification. Am J Surg Pathol 1979;3:507-23

6. Ippolito V, Brien EW, Menedez LR, et al. Case report 797. Skeletal Radiol 1993;22:604-08

7. Yamamoto T, Matsushima T, Marui T, et al. Dedifferentiated liposarcoma with chondroblastic osteosarcomatous dedifferentiation. Pathol Int 2000;50: $558-61$

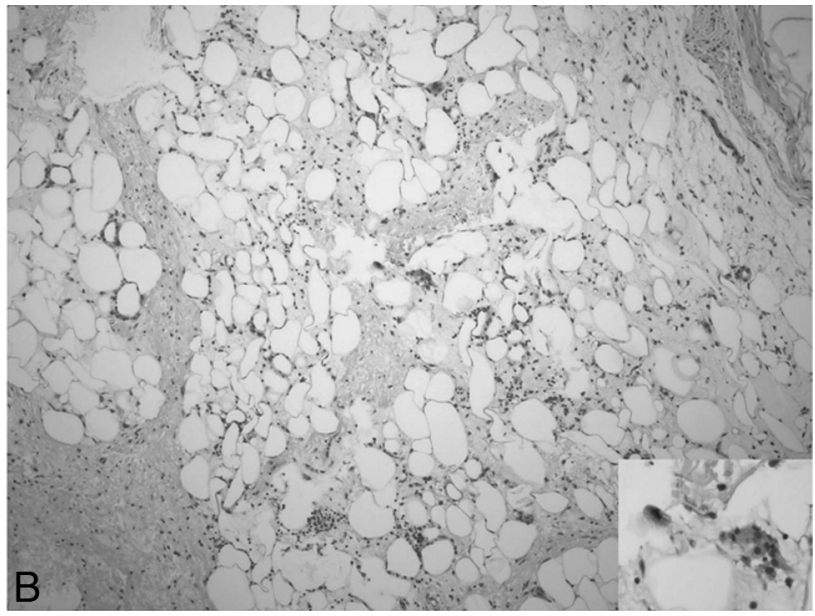

Fig 3. $A$, Photomicrographs of a biopsy specimen section obtained from the gritty nodular portion of the mass. Mineralized immature tumor bone trabeculae are present, and spindle-shaped tumor cells are seen adjacent to the tumor bone. The overall findings are consistent with osteosarcoma (HE, original magnification $\times 40)$. B, Photomicrographs of the lipoid portion. Mature-appearing adipose tissue combined with scattered lipoblasts (insert) (HE, original magnification $\times 100$; insert, original magnification $\times 400$ ). 
8. Yu L, Jung S, Hojnowski L, et al. Dedifferentiated liposarcoma of soft tissue with high-grade osteosarcomatous dedifferentiation. Radiographics 2005;25: 1082-86

9. Orui H, Ishikawa A, Tsuchiya T, et al. Chondro-osseous differentiation in fat tissue tumors: magnetic resonance imaging with pathologic correlation. Skeletal Radiol 2000;29:459-65

10. Murphey MD, Arcara LK, Fanburg-Smith J. Imaging of musculoskeletal liposarcoma with radiologic-pathologic correction. Radiographics 2005; 25:1371-95

11. Nascimento AG, Kurtin PJ, Guillou L, et al. Dedifferentiated liposarcoma: a report of nine cases with a peculiar neurallike whirling pattern associated with metaplastic bone formation. Am J Surg Pathol 1998;22:945-55

12. Ehara S, Rosenberg AE, Kattapuram SV. Atypical lipomas, liposarcomas, and other fat-containing sarcomas: CT analysis of fat element. Clin Imaging 1995; 19:50-53

13. Robson CD. Imaging of head and neck neoplasms in children. Pediatr Radiol 2010;40:499-509

14. Kransdorf MJ, Murphey M. Liposarcoma. In: Kransdorf MJ, Murphey M. Imaging of Soft Tissue Tumors. Philadelphia: Saunders; 1997:79-98
15. Miettinen M. Liposarcoma. In: Diagnostic Soft Tissue Pathology. New York: Churchill Livingstone; 2003:227-40

16. Resnick D. Tumors and tumor-like lesions of bone: imaging and pathology of specific lesions. In: Diagnosis of Bone and Joint Disorders. 4th ed. Philadelphia: Saunders; 2002:4152-55

17. Kransdorf MJ. Malignant soft-tissue tumors in a large referral population: distribution of diagnoses by age, sex, and location. AJR Am J Roentgeno 1995; 164:129-34

18. Weiss S, Goldblum J. Liposarcoma. In: Enzinger and Weiss's Soft Tissue Tumors. 4th ed. St Louis: Mosby; 2001:641-93

19. Peterson JJ, Kransdorf MJ, Bancroft LW, et al. Malignant fatty tumors: classification, clinical course, imaging appearance and treatment. Skeletal Radiol 2003;32:493-503

20. Weiss SW, Rao VK. Well-differentiated liposarcoma (atypical lipoma) of deep soft tissue of the extremities, retroperitoneum, and miscellaneous sites: a follow-up study of $\mathbf{9 2}$ cases with analysis of the incidence of "dedifferentiation." Am J Surg Pathol 1992;16:1051-58

21. McCormick D, Mentzel T, Beham A, et al. Dedifferentiated liposarcoma: clinicopathologic analysis of 32 cases suggesting a better prognostic subgroup among pleomorphic sarcomas. Am J Surg Pathol 1994;18:1213-23 